\title{
3 Advances in statistics on informal employment
}

\author{
An overview highlighting WIEGO's \\ contributions
}

\author{
Joann Vanek
}

From the beginning, WIEGO (Women in Informal Employment: Globalizing and Organizing) recognised that statistics were needed to draw public and policy attention to the size and contribution of the informal economy and the situation of women and men in it, and, therefore, it placed the development of these statistics high on its agenda. WIEGO became involved in the community and frameworks of the international statistical system while representing the reality and perspective of informal workers, particularly in the Global South, often countering the strong representation of developed countries. In this effort, WIEGO faced two major challenges. First, the measurement of the informal economy needed to be mainstreamed in labour force and economic statistics. Second, the data produced needed to be disseminated in formats that were easily accessible to researchers, policy-makers and advocates. These challenges became the objectives of the WIEGO Statistics Programme.

\section{The development of concepts and methods}

The first challenge involved developing and advocating for concepts, classifications and methods that identified and tabulated informal employment and its workers in official statistics. To do this, WIEGO worked with statisticians in the International Labour Office (ILO) and other international organisations in the regional and national statistical offices and with the International Expert Group on Informal Sector Statistics (called the Delhi Group, as it is convened by the Government of India).

In 1993, four years before WIEGO was founded, the Fifteenth International Conference of Labour Statisticians (ICLS) had adopted a standard definition of employment in the informal sector, a concept defined in terms of the characteristics of the production unit in which employment takes place (ILO 1993). This concept, however, did not reflect all of the workers of concern to WIEGO, notably informal wage workers in formal firms or households. WIEGO then advocated for a broader concept including all employment which is not covered or insufficiently covered by formal arrangements through their work, whether or not it takes place in the informal or the formal sectors. Guidelines concerning a statistical definition of informal employment were adopted by the 17th ICLS in 2003 (ILO 2003). 
The concept of informal employment is of major significance in developing countries; however, it is also relevant in developed countries where employment arrangements frequently and increasingly leave workers with no formal social protection or worker benefits. In 2007, WIEGO began working on a new statistical priority, namely, to develop a common framework for labour statistics relating to both developed and developing countries. With the ILO, WIEGO organised a conference on the topic in 2008 at Harvard University and continues this work through the Economic Commission for Europe Expert Group on Quality of Employment. A WIEGO Statistical Brief, "Relating Quality of Employment to Informal Employment", details the importance and relevance of the definition of informal employment to the economies of developed countries and to the study of trends in the structure of employment across all countries (Carré, Negrete and Vanek 2016).

The classification of labour statistics that has the most relevance to informal employment is the International Classification of Status in Employment (ICSE). This standard provides information on the nature of the economic risk and authority that the employed population experience at work. A revision of the 1993 version of this classification was requested by the 19th ICLS to provide the information required to adequately monitor the changes in employment arrangements taking place in many countries, for example, the growth of non-standard forms of employment. Dependent contractors, homeworkers and other industrial outworkers - groups of concern to WIEGO - are not well reflected in ICSE-93. WIEGO prepared a paper with proposed considerations for the revision of the ICSE-93 and was selected to be among the experts in the working group preparing for the review of the ICSE-93 by the 20th ICLS (ibid.). In October 2018, the 20th ICLS approved the Resolution concerning Statistics on Work Relationship (designated as ICSE-18), which reflects the proposed revisions. The elements of the Resolution that are of particular concern to WIEGO include: a new status category (Dependent Contractors) which reflects the situation of many informal workers, including that of homeworkers, and the inclusion of place of work, domestic workers and job-related social protection coverage as essential cross-cutting variables and categories.

In several ways, WIEGO encourages and provides technical support to countries to collect data on informal employment, including adopting the new definitions and methods. With the International Labour Organization (ILO), and the Delhi Group, WIEGO was a member of the team which prepared a manual providing technical guidance to countries on designing and implementing surveys of employment in the informal sector and informal employment (ILO 2013a). WIEGO also organised and collaborated on training efforts in countries and in regions. For example, with the ILO, the Economic and Social Commission for Asia and the Pacific (ESCAP) and the Japanese Government, WIEGO co-led two courses on statistics on the informal economy at the Statistical Institute for Asia and the Pacific, the first in the summer of 2015 and the second in the fall of 2017. These courses trained 48 national statisticians and labour ministry officials from 27 Asian countries. 
WIEGO has developed a Statistical Brief Series which includes briefs on methods for the collection, classification, tabulation and analysis of official national statistics on the informal economy and specific groups of informal workers. The statistical challenge in these briefs is generally not how to capture these workers as employed but rather how to identify and classify the category of work or occupation in which they are employed. In part, this challenge arises because these groups tend to be in employment arrangements that are more difficult to measure and classify than workers in formal arrangements. It also arises because these groups are not well reflected in the standard international and national classifications for employment. Special methods are often needed in data collection and tabulation, as well as classification, to identify these workers.

The United Nations Sustainable Development Agenda provides a major incentive for improvement of data to support the monitoring of progress in implementing the goals and targets of the 2030 Agenda. In particular, the selection of "the share of informal non-agricultural employment" proposed by the ILO and WIEGO, as Indicator 8.3.1 under Sustainable Development Goal 8, raises the priority of data on informal employment in the agendas of national statistical offices. This should increase the availability of statistics on the topic. WIEGO's work to promote globally the development of statistics on informal employment has contributed to the selection of this indicator.

\section{The dissemination of statistics}

The second main challenge of the WIEGO Statistics Programme was to put statistics on the informal economy in the hands of users - ranging from researchers, policy-makers and officials, to advocates and organisations of informal workers. Each of these sets of potential users requires data in different formats - microdata sets and databases for researchers, concise reports on the main statistics available for policy-makers, and targeted briefs focusing on specific groups of workers for advocates and organisations of informal workers.

In 2002, the ILO published the first international compilation of statistics on the informal economy with estimates for the developing regions and the best available data on two groups of informal workers - street vendors and homebased workers (ILO 2002b). The report, Women and Men in the Informal Economy: A Statistical Picture, was prepared by a WIEGO team to support the General Discussion on Decent Work and the Informal Economy at the 90th Session of the International Labour Conference, Geneva, in June 2002.

In 2013, ILO published the second edition of Women and Men in the Informal Economy: A Statistical Picture (ILO and WIEGO 2013). The publication was a collaboration between ILO and WIEGO. It featured national data in the ILOWIEGO Database on the Informal Economy, another outcome of the ILO and WIEGO collaboration. A second set of estimates on the informal economy in developing regions based on these data was published as a WIEGO Working Paper, "Statistics on the Informal Economy: Definitions, Regional Estimates and Challenges" (Vanek et al. 2014). 
Comparing the methods used and the data available in preparing the two sets of estimates shows the progress made in the development of statistics on informal employment. The estimates in the first edition of Women and Men in the Informal Economy: A Statistical Picture (ILO 2002b) were based on residual or indirect measures of informal employment for only 25 countries. The second set of estimates in the WIEGO Working Paper was based on direct measures of informal employment in 40 countries and indirect measures in 81 countries and a sophisticated and robust analytic approach combing direct and indirect measures.

The third edition of Women and Men in the Informal Economy: A Statistical Picture, published in 2018, was prepared by the ILO with technical advice from WIEGO (ILO 2018a). It advances the field in several important ways: for the first time, (1) statistics on the informal economy are presented at the global level, based on developed as well as developing countries and including agriculture as well as non-agricultural sectors; (2) a common set of criteria were used to measure informal employment inside and outside the informal sector; and (3) micro-data from over 100 countries were processed to produce the national, regional and global estimates. To make these estimates accessible in a user-friendly format to a wider audience, ILO and WIEGO also collaborated on the publication of Women and Men in the Informal Economy: A Statistical Brief (Bonnet, Vanek and Chen 2019). Finally, WIEGO produced the key statistics and statistical messages in a pamphlet Counting the World's Informal Workers: A Global Snapshot (ILO-WIEGO 2018).

Given the urban focus of much of WIEGO's work, the development of citylevel statistics on informal employment and groups of urban workers - domestic workers, home-based workers, market traders and street vendors and waste pickers - is a high priority for WIEGO and organisations of these workers. As of mid-2019, WIEGO had commissioned data on informal employment and specific groups of informal workers in 19 cities and presented it as a section of the WIEGO Dashboard (WIEGO n.d.) These data - as well as the national and regional data in the Dashboard - are based on official statistics. The national and regional components of the Dashboard are being updated with the new ILO estimates. WIEGO is also updating the city-level data and publishing them in the WIEGO Statistical Brief series.

The WIEGO Statistical Brief series not only covers the methodological topics outlined above but also provides statistics in accessible formats on informal employment and specific groups of informal workers. Some of the briefs present statistics at the regional level while others present data at the country, urban or city levels. The production of these briefs has largely been in response to requests by organisations of informal workers and also by the WIEGO Urban Policies and Focal Cities teams.

\section{Final note}

Since WIEGO was founded in 1997, great advances have been made in providing statistics on the informal economy. As this chapter highlights, WIEGO has 
made an important contribution to these advances, at times being the driving force behind them. Informal employment is becoming an integral part of mainstream labour statistics, for example, ILO now integrates data on informal employment into its main database, ILOSTAT. Moreover, the first-ever global statistics on informal employment are now available based on the 2018 ILO harmonised estimates. Thanks to these global estimates, we now know that:

- More than 60 per cent of total employment worldwide is informal.

- Around 90 per cent of employment in developing countries and 67 per cent in emerging countries is informal.

- Globally, 44 per cent of all workers are self-employed and 60 per cent of informal workers are self-employed. In developing countries, 72 per cent of all workers and 80 per cent of informal workers are self-employed. And in emerging countries, 49 per cent of all workers and 63 per cent of informal workers are self-employed. 